\title{
Caspase-1 is a novel target of p63 in tumor suppression
}

\author{
I Celardo ${ }^{1}$, F Grespi ${ }^{1}$, A Antonov ${ }^{1,2}$, F Bernassola ${ }^{3,4}$, AV Garabadgiu² ${ }^{2}$, G Melino ${ }^{*, 1,3}$ and I Amelio ${ }^{*, 1}$
}

p63 is a p53 family transcription factor, which besides unique roles in epithelial development, shares tumor suppressive activity with its homolog p53. The p63 gene has different transcriptional start sites, which generate two N-terminal isoforms (transactivation domain (TA)p63 and amino terminal truncated protein $(\Delta \mathrm{N}) \mathrm{p} 63$ ); in addition alternative splicing at the $5^{\prime}$-end give rise to at least five $\mathrm{C}$-terminal isoforms. This complexity of gene structure has probably fostered the debate and controversy on p63 function in cancer, with TP63-harboring two distinctive promoters, codifying for the TAp63 and $\Delta$ Np63 isoforms, and having discrete functions. However, $\Delta$ Np63 also drives expression of target genes that have a relevant role in cancer and metastasis. In this study, we identified a novel p63 transcriptional target, caspase-1. Caspase-1 is proinflammatory caspase, which functions in tumor suppression. We show that both p63 isoforms promote caspase-1 expression by physical binding to its promoter. Consistent with our in vitro findings, we also identified a direct correlation between p63 and caspase- 1 expression in human cancer data sets. In addition, survival estimation analysis demonstrated that functional interaction between p63 and caspase-1 represents a predictor of positive survival outcome in human cancers. Overall, our data report a novel p63 target gene involved in tumor suppression, and the clinical analysis underlines the biological relevance of this finding and suggests a further clinically predictive biomarker.

Cell Death and Disease (2013) 4, e645; doi:10.1038/cddis.2013.175; published online 23 May 2013

Subject Category: Cancer

p63 is a transcriptional factor, which together with p73 belongs to the p53 family. ${ }^{1,2}$ It is expressed as two different isoforms: the full length transactivation domain (TA) isoforms (TAp63), which contain the $\mathrm{N}$-terminal transactivation domain, and the $\Delta \mathrm{N}$ (amino terminal truncated protein) isoforms $(\Delta \mathrm{Np} 63)$, which, generated by an alternative internal promoter, produces a N-terminally truncated isoform, lacking the $\mathrm{N}$-terminal transactivation domain. ${ }^{3,4}$ In addition, alternative splicing at the $\mathrm{C}$-terminus produce at least three further isoforms, giving rise to $\alpha, \beta$ and $\gamma$ isoforms. ${ }^{5} \Delta \mathrm{Np} 63$ also has transcriptional activity owing to a second downstream transactivation domain, TA2. ${ }^{6}$

The $\Delta \mathrm{Np63}$ isoform is a master regulator of epithelial development. It is mainly expressed in the basal layer of the epidermis and other epithelia. The full p63-null and the $\Delta$ Np63 selective-null mice die shortly after birth, with loss of stratified epithelia and truncated limbs and cleft palate. ${ }^{7-10}$ Like $p 53,{ }^{11-13}$ TAp63 isoforms can have a role in promoting DNA damage-dependent cell cycle arrest and apoptosis. TAp63 isoforms, indeed, are expressed in response to DNA damage; conversely, $\Delta \mathrm{Np} 63$ is degraded in response to genotoxic stress. ${ }^{14}$ TAp63 shares with p53 several target genes ${ }^{15,16}$ involved in cell cycle arrest and apoptosis, such as PUMA, ${ }^{17} \mathrm{BAX}^{18-20}$ and CDKN1A (p21); ${ }^{13,21}$ thus, TAp63 isoforms exert tumor suppressor activity. ${ }^{22}$ In addition, TAp63 is highly expressed in oocytes and has a unique role as guardian of the germ line. ${ }^{23,24}$ Oocytes from TAp63 knockout mice, indeed, do not undergo cell cycle arrest and apoptosis upon DNA damage. ${ }^{2,25}$ p63 is expressed in a wide range of human cancers, such as prostate, ${ }^{26}$ bladder, ${ }^{27}$ lung, ${ }^{28}$ breast $^{29-31}$ and cervix. ${ }^{32,33}$ p63 is rarely mutated in cancer, although frequently altered expression and function has been observed. ${ }^{34}$ In epithelial cancer cells, p63 counteracts TGF- $\beta$-mediated invasiveness and metastasis. Mutant-p53 can antagonize this p63 metastasis suppressor activity, ${ }^{35,36}$ forming a ternary complex with Smad and p63. ${ }^{37-39}$ This highlights the complexity of p63 function in tumorigenesis due to its different $\mathrm{N}$-terminal isoform roles, tissue-specific expression and interaction with other paralogue genes, p53 and p73.

Caspases are a class of cysteine-proteases involved in regulation of inflammation and apoptosis. ${ }^{40,41}$ Caspase-1, also known as interleukin- $1 \beta$ converting enzyme, is activated by inflammosomes, multiprotein complexes formed by caspase-1, several members of the NOD-like receptors family and the adaptor protein ASC. Active caspase-1 catalyzes the proteolytic maturation of cytokine substrates pro-IL1 $\beta$ and pro-IL-18, respectively into IL-1 $\beta$ and IL-18 active forms.

\footnotetext{
${ }^{1}$ Medical Research Council, Toxicology Unit, Leicester University, Leicester LE1 9HN, UK; ${ }^{2}$ Saint-Petersburg State Institute of Technology, Saint-Petersburg, Russia; ${ }^{3}$ Department of Experimental Medicine and Surgery, University of Rome 'Tor Vergata', Rome, Italy and 'Department of Experimental Oncology, European Institute of Oncology, Milan, Italy

*Corresponding author: G Melino or I Amelio, Medical Research Council, Toxicology Unit, Leicester University, Leicester LE1 9HN, UK. Tel: +44 01162525592 ; Fax: + 440116252 5616; E-mail: gm89@le.ac.uk or ia119@le.ac.uk

Keywords: p63; tumor suppression; caspase-1; prostate cancer; bladder cancer; breast cancer

Abbreviations: TA, transactivation domain; $\Delta \mathrm{N}$, amino terminal truncated protein; Doxy, doxycycline; RE, responsive element; qPCR, quantitative polymerase chain reaction

Received 06.4.13; accepted 22.4.13; Edited by RA Knight
} 
In addition to its well-established proinflammatory role, caspase-1 can also execute a program of cell death, termed pyroptosis, to kill infected macrophages. ${ }^{42}$ However, caspase-1 retains a direct role in non-infectious cell death processes. $^{43}$ Caspase-1, indeed, also acts as a tumor suppressor regulating proliferation and apoptosis of epithelial cells. Caspase-1-deficient mice show enhanced tumor formation in the azoxymethane and dextran sodium sulfate colitis-associated colorectal cancer models. ${ }^{44,45}$ Moreover, in human cancers, caspase-1 is frequently downregulated, especially in prostate cancer. ${ }^{46,47}$

In the present study, we report that p63 is a positive regulator of caspase- 1 expression. We demonstrated that p63 directly regulates caspase- 1 protein and RNA levels, through a direct binding to the caspase-1 promoter. Strikingly, our data are supported by the finding that positive correlation between p63 and caspase-1 expression represents a positive predictor of survival outcome in different human cancer data sets. Our work highlights a novel p63 target, which contributes to p63 tumor suppressor function.

\section{Results}

TAp $63 \alpha$ and $\Delta \mathrm{Np} 63 \alpha$ drive caspase- 1 induction. p63 is a transcriptional factor involved in cancer and metastasis. In many cancer types, the loss of p63 expression is associated with increased tumorigenesis ${ }^{48}$ and metastasis. ${ }^{49}$ Caspase- 1 knockout mice show enhanced tumor formation associated with increased cell proliferation and reduced apoptosis. ${ }^{44}$ Therefore, we decided to evaluate a possible association between p63 function and caspase- 1 expression. To this end, we used SaOs-2 Tet-On cell lines, which carry inducible expression systems for $\mathrm{TAp} 63 \alpha$ or $\Delta \mathrm{Np} 63 \alpha$. As shown in Figures $1 \mathrm{a}$ and $\mathrm{b}, 4 \mu \mathrm{g} / \mathrm{ml}$ doxycycline (Doxy) treatment strongly induced expression of both p63 isoforms. Western blot analysis showed that in both TAp63- and $\Delta$ Np63expressing cell lines caspase-1 protein was induced in a time-dependent fashion, in parallel with the expression of the transcriptional factor (Figures $1 \mathrm{a}$ and $\mathrm{b}$ ). To evaluate whether caspase-1 upregulation was associated with induced transcription of the casp-1 gene, we performed additional analysis by real-time quantitative polymerase chain reaction (qPCR) in SaOs-2 Tet-On cell lines. qPCR confirmed upregulation of caspase-1 mRNA with a kinetics consistent with the well-known p63 transcriptional target, p21 (Figures $1 \mathrm{c}$ and $\mathrm{d}) .{ }^{22}$ Collectively, this data demonstrate that both $\mathrm{p} 63$ isoforms can regulate caspase- 1 expression and also suggest that p63 might directly act on the caspase-1 promoter regulating its expression at the transcriptional level.

p63 transactivates the caspase-1 promoter. As the above results indicated a transcriptional effect of TAp63 $\alpha$ and $\Delta \mathrm{Np} 63 \alpha$ on the caspase- 1 promoter, we next explored whether p63 isoforms were able to directly bind a responsive element (RE) in the promoter region. As a first approach, we performed a bioinformatics analysis to identify putative consensus p53 REs in the promoter sequence of human caspase-1. We used Matlnspector Professional software, which allows identification of p53-like REs. Within the first $1600 \mathrm{bp}$, we identified one putative binding site, which was located between $-94 \mathrm{bp}$ and $-117 \mathrm{bp}$ from the transcriptional start of the caspase-1 gene (Figure 2a). To experimentally validate our hypothesis, we utilized a reporter gene vector, which contained this promoter region upstream of the
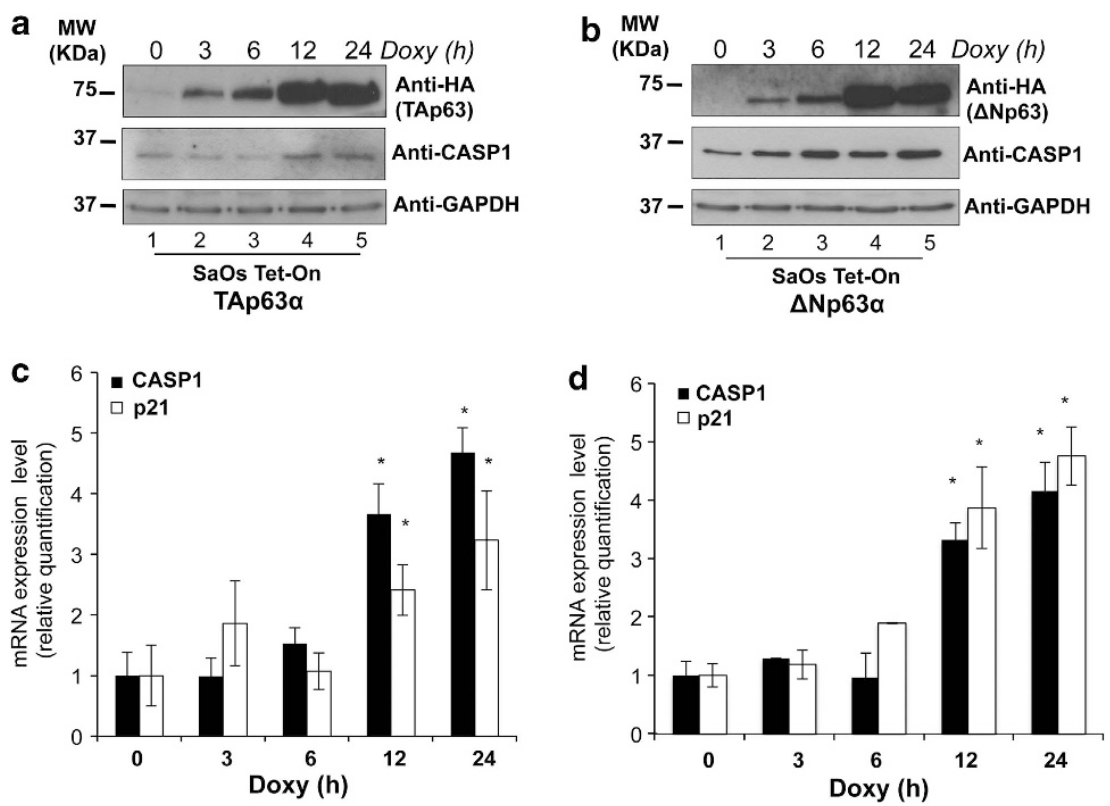

Figure 1 p63 upregulates protein and mRNA levels of caspase-1. (a and $\mathbf{b}$ ) Caspase-1 protein is induced by both p63 isoforms in a time-dependent manner. TAp63 $\alpha$ (a) and $\Delta \mathrm{Np} 63 \alpha$ (b) SaOs-2 inducibile cells were treated with $4 \mu \mathrm{g} / \mathrm{ml}$ Doxy to induce p63 expression. After 3, 6, 12, 24 (h) of p63 induction, a western blot analysis was performed using the indicated antibodies. GAPDH levels were evaluated as a control. The experiment shown is representative of three independent experiments. (c and $\mathbf{d}$ ) mRNA expression of caspase-1 was induced by p63. Levels of caspase-1 were evaluated by real-time qPCR following TAp63 $\alpha$ (c) and $\Delta$ Np63 $\alpha$ (d) induction at the same time indicated for western blot analysis. p21 was used as positive control. Relative expression of caspase-1 and p21 were normalized against TBP and calculated as fold induction. Data represent mean \pm S.D. of three different experiments analyzed in triplicate. ${ }^{*} P<0.05$ 
a

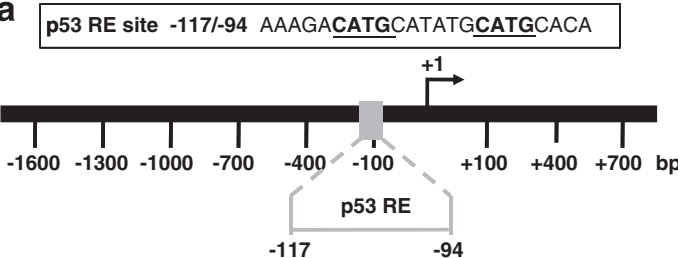

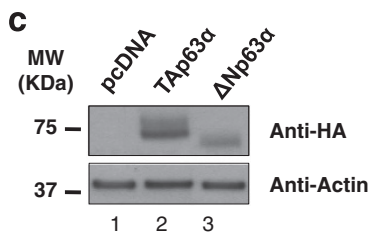

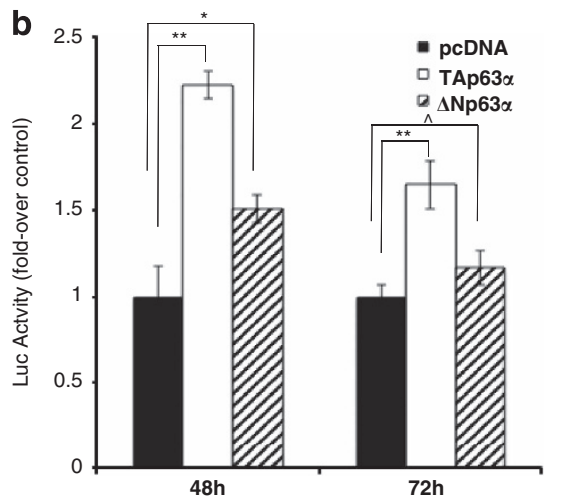

d

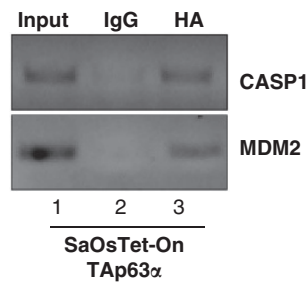

Figure 2 p63 directly transactivates the caspase-1 promoter. (a) Schematic map of the human caspase-1 promoter region with the p53-like RE. The insert shows the sequence of the p53-RE, located between -94 and -117 bp upstream of the transcription-start site. (b) Both TAp63 $\alpha$ and $\Delta$ Np63 $\alpha$ isoforms transactivate the caspase-1 promoter at $48 \mathrm{~h}$. Caspase- 1 promoter activity was evaluated after co-transfection with pcDNA vector, TAp63 $\alpha \Delta N p 63 \alpha$ plasmids. The luciferase assay was performed after 48 and $72 \mathrm{~h}$ of co-transfection in 293T cells and was normalized by co-transfection of Renilla vector. The graphs show a mean \pm S.D. of three different experiments. ${ }^{* \star} P<0.001$; ${ }^{*} P<0.05 ; \wedge P=0.1$. (c) Western blot analysis from the same lysates as the luciferase assay performed as control to show the $\mathrm{p} 63$ protein expression. (d) SaOs-2 cells were induced with $4 \mu \mathrm{g} / \mathrm{ml}$ Doxy for $24 \mathrm{~h}$. The sonicated chromatin was bound to TAp63 $\alpha-\mathrm{HA}$ and amplified by PCR with caspase-1 primer that recognizes the p53-response element (from -94 to $-117 \mathrm{bp}$ ). ChIP on MDM2 promoter was performed as a positive control. Mouse IgG antibody was used as a negative control of the ChIP procedure

luciferase reporter gene. 293T cells were then co-transfected with reporter plasmid and $\mathrm{TAp} 63 \alpha$ or $\Delta \mathrm{Np} 63 \alpha$ isoform expressing plasmids. To verify transfection efficiency, western blotting for TAp63 $\alpha$ and $\Delta \mathrm{Np} 63 \alpha$ was performed on the same protein extracts as used in the luciferase assays (Figure 2c). Consistent with our hypothesis, after 48 and $72 \mathrm{~h}$ of transfection the luciferase assays showed significant increase of luciferase activity in presence of one of the two p63 isoforms (Figure 2b), suggesting a direct ability of p63 to affect transcriptional regulation of caspase-1. These data strongly suggest that caspase- 1 might represent a transcriptional target of p63.

p63 physically binds the caspase-1 promoter. To finally confirm that a transcriptional factor directly regulates expression of a downstream target, it is crucial to assess the direct binding on the promoter RE. Hence, to address this question, we performed a chromatin immunoprecipitation (ChIP) for the p53-like RE included in the caspase-1 promoter, in p63 overexpressing cells. We induced TAp63 $\alpha$ expression by Doxy treatment in SaOs-2 TET cells for $24 \mathrm{~h}$. The immunoprecipitated chromatin was then utilized to perform a PCR with a primer pair designed to amplify the p53-RE region included in the caspase-1 promoter (Figure 2d). The specific PCR band was specifically detected only in the anti-HA immunoprecipitated chromatin, when compared with anti-IgG immunoprecipitated control chromatin. Hence, the ChIP demonstrated the physical interaction of p63 with the p53-like RE in the caspase-1 promoter. We, therefore, conclude that caspase- 1 is a de novo transcriptional target gene of $p 63$. p63 correlates with caspase-1 expression in human cancers. We next performed bioinformatic correlation analysis between caspase- 1 and p63 expression in three different human cancer data sets. Identification of a correlation between p63 and caspase-1 in human cancers would lend clinical relevance to our findings. To perform the bioinformatic analysis we selected two prostate cancer data sets and one bladder cancer data set. Prostate cancer data sets, Arredouani et al. ${ }^{50}$ and Varambally et al., ${ }^{51}$ comprised 21 and 19 patients, respectively (Figure 3a), while the 'Stransky' bladder dataset ${ }^{52}$ included 57 patients (Figure 3b). Coexpression analysis showed direct association between p63 and caspase-1 mRNA levels. The Arredouani prostate data set presented a correlation factor of 0.446 , and Varambally prostate data set of 0.859 (Figure 3a). Consistently a positive association with a correlation factor of 0.368 was also found in the Stransky bladder data set (Figure 3b). Plotting the expression level of both prostate and bladder data sets on a graph clearly showed the positive linearity of the association. Samples with low p63 levels also showed reduced caspase-1, whereas samples with high p63 levels showed caspase-1 upregulation (Figures $3 c$ and d). Strikingly, these data lend important biological relevance to our findings. In human epithelial cancers, dysregulation of p63 can result in a consequent dysregulation of caspase-1, thus potentially affecting tumorigenesis.

Positive correlation between p63 and caspase-1 is a predictor of better survival outcome in breast cancer patients. To further investigate clinical relevance of p63dependent caspase-1 regulation, we evaluated the biological 
a

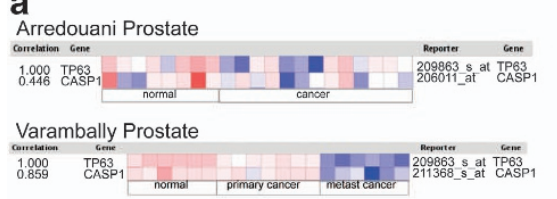

b

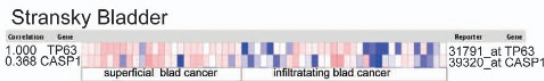

C

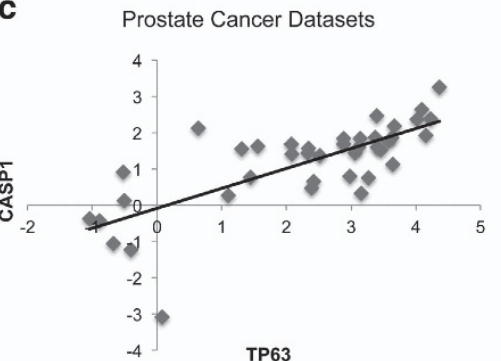

d

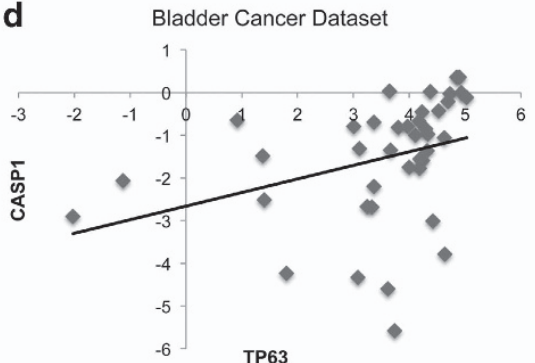

Figure 3 p63 and caspase-1 expression directly correlate in human prostate and bladder cancers. (a and b) Expression data from the Oncomine website (http://www.oncomine.org). We used the following filters: gene 'TP63'; Analysis Type: 'Coexpression analysis'; Cancer Type: Prostate Cancer (a) or Bladder Cancer (b). The color changes according to a weaker (blue) or higher (red) expression, passing by white, with fluctuating color intensity. The reporters indicate probes used for the analysis. (a) Considering the maximum correlation 1, caspase-1 has a correlation of 0.446 , in Arredouani and 0.859 , in Varambally prostate cancers. The Arredouani data set was performed on mRNA samples of 8 normal prostates and 13 prostate cancers. In the Varambally data set, mRNA of six hormone-refractory metastatic prostate carcinoma samples, seven primary prostate carcinoma samples, and six normal prostate gland samples were analyzed. Both data sets were performed with Human Genome U133 Plus 2.0 Array and 19574 genes were measured. (b) In the Stransky bladder data set, caspase-1 shows a correlation with TP63 of 0.368 ; in this data set, mRNA from 8603 genes on 25 superficial bladder cancer and 32 infiltrating bladder urothelial carcinomas were analyzed using Affymetrix U95A microarrays. (c and d) The graphs are obtained from the expression values of TP63 and caspase-1 on the prostate (c) and bladder (d) data sets; the straight lines indicate that the correlation between caspase-1 and TP63 genes is direct. All three data sets are selected using as threshold a $P$-value of 0.01

consequence of p63/caspase-1 axis disruption in human cancers. We used three publicly available breast cancer gene expression data sets annotated with patient survival data. In contrast to the standard approach, where patients are grouped based on high/low expression of a gene (or a gene signature which is a weighted sum of expression of several genes), we implemented a statistical procedure, which splits patients into two cohorts based on a different principle. Namely, in the first cohort we selected patients so as to maximize positive correlation between p63 and caspase-1, while all the other patients formed the second cohort (Figures $4 \mathrm{a}-\mathrm{c}$ left and central panels). Thus, we clustered the samples into two biological groups: one where the p63/caspase-1 axis was present, and the second in which it was absent. To identify statistical differences in survival outcome between the two groups of patients, the $R$ statistical package was used to perform statistical tests and to derive the $P$-value (for full details of the procedure see method section). Each data set showed that the cohort of patients with a strong positive correlation between p63 and caspase-1 showed improved survival outcome compared with the cohort where the p63/caspase-1 axis was disrupted (Figure 4c right panels). Notably, each of the considered data sets with low/high expression of either p63 or caspase-1 alone did not correlate with survival (data not shown). Overall, these results suggest that the presence/absence of p63/caspase-1 interactions could serve as a promising cancer biomarker of patient survival. In conclusion, our findings further elucidate p63 tumor suppressor function and also provide additional knowledge for identification of novel cancer biomarkers.

\section{Discussion}

Our analysis of expression levels in human cancer data sets shed light on a novel correlation between $\mathrm{p} 63$ and caspase-1 expression in cancers. In addition, retention of the p63/ caspase-1 axis in human breast cancer represents a predictor of good survival outcome. p63 is rarely mutated in human cancers, but frequently the expression levels are altered. Its function in epithelial development might suggest the relevance of p63 in tumors of epithelial origin, such as bladder, prostate and breast. p63 is essential for development of the ventral part of the urinary bladder ${ }^{53}$ and it is usually expressed in bladder urothelial carcinoma cells. ${ }^{54}$ In agreement with our findings, $\triangle$ Np63 and TAp63 are frequently downregulated in bladder cancer and this reduction correlates with poor prognosis. $^{55}$ Similarly to bladder, prostate cancer also requires p63 expression for its development and it is used diagnostically to differentiate prostate cancer from benign mimickers. ${ }^{56}$ The majority of prostate cancers show loss of p63, but it is overexpressed in some poorly differentiated tumors and correlates with a poor prognosis. ${ }^{57}$ In addition, loss of p63 results in enhanced metastasis in prostate cancer. $^{38}$

Caspase-1 can represent a crucial downstream mediator of p63 tumor suppression function. In our clinical data sets, lack of a p63/caspase-1 correlation predicts poor survival outcome. Our in vitro studies show evidence of a physical interaction between $\mathrm{p} 63$ and the caspase-1 promoter, by which p63 can act as a direct transcriptional factor for caspase-1. Furthermore, we demonstrated that both TAp63 $\alpha$ and $\Delta$ Np63 $\alpha$ isoforms transactivate the promoter of 

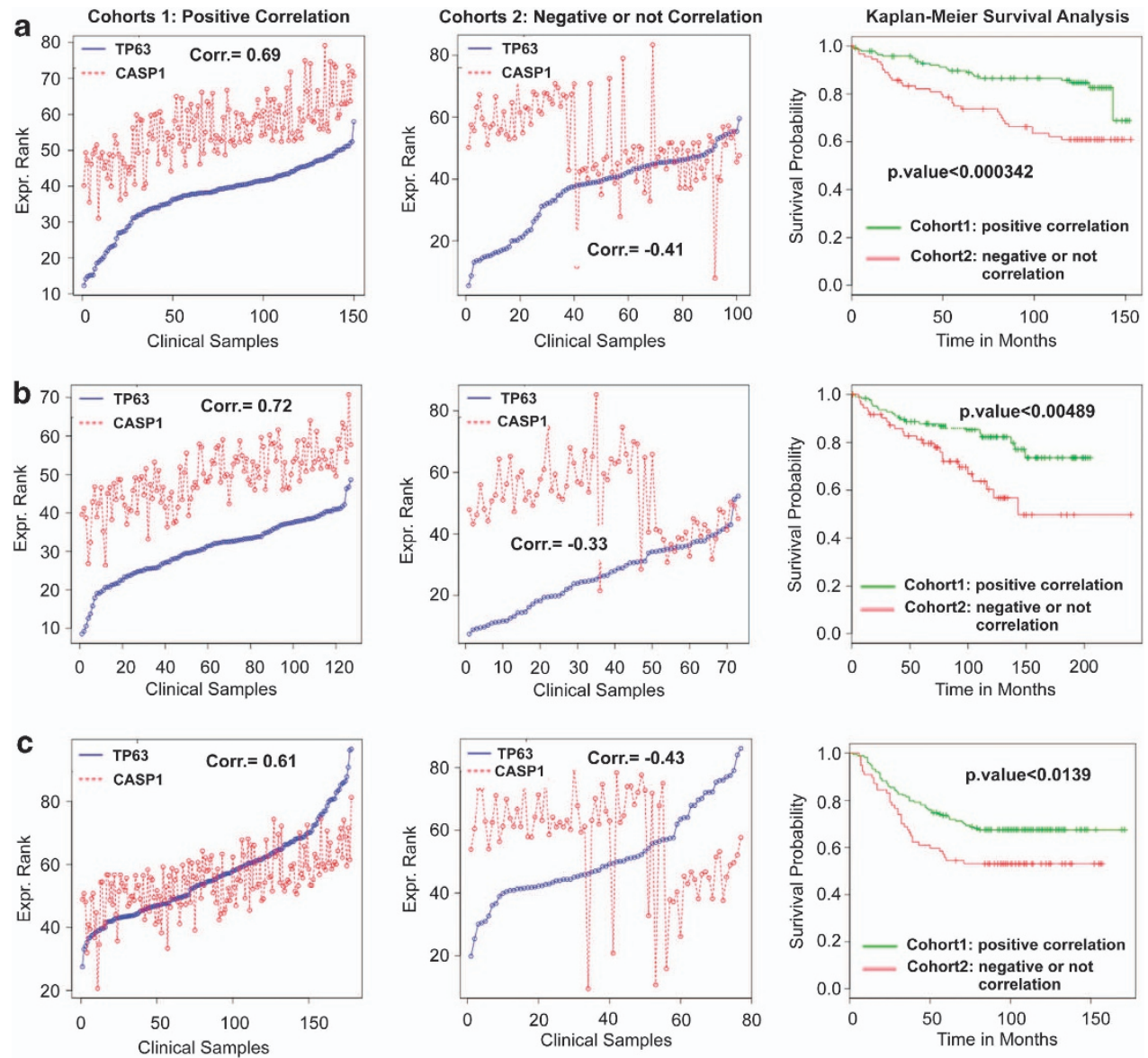

Figure 4 Positive p63/caspase-1 correlation represents a prognostic factor for good patient survival. (a-c) Three different human breast cancer data sets have been analyzed: GSE3494 (a), GSE11121 (b), GSE2034 (c). Left and central panels represent p63 and caspase-1 expression profiles in the cohorts 1 (positive correlation) and cohorts 2 (negative or absent correlation). Right panels represent patient survival estimation of p63/caspase-1-positive correlation groups compared with negative or absent correlation groups

caspase-1, resulting in an increase of luciferase activity. Much evidence have shown that $\mathrm{p} 63$ is related to tumor progression, but the underlying molecular mechanisms are still under investigation. Here, we report that caspase- 1 is a transcriptional target of p63, working at downstream level in the cell death pathway induced by $\mathrm{p} 63$ to counteract carcinogenesis. Indeed, although caspase-1 is the main mediator of a proinflammatory response and chronic inflammation, it is also associated with tumor development. There is also direct evidence that caspase- 1 is an apical activator of cell death, ${ }^{43}$ and its loss is associated with enhanced tumor formation in a colitis-associated colorectal mouse cancer model. ${ }^{44,45}$ Furthermore, caspase- 1 is downregulated in the majority of human prostate cancers, and its reintroduction induces higher sensitivity to radiation-induced cell death. ${ }^{46}$ These findings are consistent with the downregulation of p63 found in human prostate cancer. ${ }^{38,57}$

In conclusion, our data shed light on the functional interaction between p63 and caspase-1, thus providing additional evidence on the tumor suppressor mechanism of p63 and suggesting potential future clinical biomarkers for epithelial human cancers.

\section{Materials and Methods}

Cell cultures. All cell lines used were maintained at $37^{\circ} \mathrm{C}$ in $5 \% \mathrm{CO}_{2}$ in culture medium. 293T cells were grown in RPMI, $250 \mu \mathrm{M}$ sodium pyruvate (Gibco, Grand Island, NY, USA), $250 \mu \mathrm{M}$ L-glutamine (Gibco), penicillin/streptomycin 1 unit/ml (Gibco), 10\% (vol/vol) FCS (Invitrogen, Carlsbad, CA, USA); TAp63 $\alpha$ and $\Delta \mathrm{Np} 63 \alpha$ SaOS-2-Tet-On cells were grown in RPMl, $250 \mu \mathrm{M}$ L-glutamine (Gibco), penicillin/streptomycin $1 \mathrm{unit} / \mathrm{ml}$ (Gibco) and 10\% (vol/vol) Tet-free FCS (Clontech, Mountain View, CA, USA). To generate SaOS-2 clones with the inducible expression of p63 isoforms (Tet-On system), we used a clone of SaOS-2 cells expressing the Tet-responsive transcriptional activator rtTA.

Cell transfection and luciferase assay. A total of $1 \times 10^{5} 293 \mathrm{~T}$ cells were seeded in 12-well dishes $24 \mathrm{~h}$ before transfection. $300 \mathrm{ng} / \mathrm{well}$ of $\mathrm{pGL} 3$ vector, HAtagged TAp63 $\alpha$ and $\Delta \mathrm{Np} 63 \alpha$ plasmids, $100 \mathrm{ng} /$ well caspase- 1 luciferase reporter plasmid and $2 \mathrm{ng} / \mathrm{well} \mathrm{pRL}$-cytomegalovirus vector were co-transfected using Effectene reagent (Qiagen, Manchester, UK). Luciferase activities of cellular extracts were measured $48 \mathrm{~h}$ and $72 \mathrm{~h}$ after transfection using a Dual-Luciferase Reporter Assay System (Genecopoeia, Rockville, MD, USA). Light emission was measured over $5 \mathrm{~s}$ using a luminometer (with Glomax 96 Microplate Luminometer, Promega (Madison, WI, USA). Efficiency of transfection was normalized using Renilla luciferase activity.

Analysis of promoter region. A region $1317 \mathrm{~kb}$ upstream of the transcriptionstart site of the human caspase-1 gene was analyzed using Math-Inspector Professional software and the TRANSFAC database. ${ }^{58}$ The analysis revealed the presence of a p53-like RE located at $-94 \mathrm{bp}$ upstream of the transcription-start site. The caspase1 promoter plasmid was purchased from Genecopoeia (vector: pEZX-PG02). 
Immunoblot analysis. Proteins from SaOs-2 cells were extracted with RIPA buffer containing inhibitor cocktails (Roche, Madison, WI, USA) and homogenized by using QIAshredder (Qiagen). Concentration was determined using a Bradford dyebased assay (Bio-Rad, Hercules, CA, USA). Total proteins were loaded on 10\% SDSPAGE and transferred to polyvinylidene difluoride membranes (Hybond; GE Healthcare, Piscataway, NJ, USA). Membranes were blocked and incubated with primary and secondary antibodies in PBST (PBS with Tween 20) and 5\% non-fat dry milk. The antibodies against caspase-1 $(1: 500)$ and GAPDH $(1: 10.000)$ were from Sigma-Aldrich, (St Louis, MO, USA). The anti-HA (1:100) antibody was from Covance, (Princetown, NJ, USA). Following incubation with the relevant horseradish peroxidaseconjugated secondary antibodies, detection was carried out with ECL (Amersham).

RNA extraction and quantitative real-time PCR. Total RNA was extracted from SaOS-2 cells by using the RNeasy Mini Kit (Qiagen) and quantified by spectrophotometric analysis. One microgram of total RNA was reverse transcribed using the InPromll kit (Promega) and $1 / 5$ of the reaction was used for PCR. Real-time PCR was performed using the SYBR green ready mix (Applied Biosystems). The primers used were: Casp-1 (+ TGCCTGTTCCTGTGATGTGG, _TGTCCTGGGAAGAGGTAGAAACATC); p21 (+ TGGGGATGTCCGTCAGAAC, _GGCGTTTGGAGTGGTAGAAATC); TBP (+ TCAAACCCAGAATTGTTCTCCTT AT, _CCTGAATCCCTTTAGAATAGGGTAGA). TBP was used as a housekeeping gene for quantity normalization; relative quantification of gene expression was calculated according to the method of $2^{-\Delta \Delta \mathrm{Ct}}$ described in the User Bulletin no. 2 and the Relative Quantification software version 1.3 of Applied Biosystems.

Chromatin immunoprecipitation assay. SaOs-2 cells were treated for $24 \mathrm{~h}$ with $4 \mu \mathrm{g} / \mathrm{ml}$ Doxy to induce p63 expression. Cells were collected at $80 \%$ confluency and fixed in $37 \%$ formaldehyde. Chromatin was sheared by sonication and immunoprecipitated for $2 \mathrm{~h}$ with/without $10 \mu \mathrm{l}$ of anti-HA antibody (Covance) with a ChIP assay kit (Invitrogen). The co-immunoprecipitated promoter fragments and input DNA were amplified by PCR. MDM2 was used as positive control. The primers used were: Caspase-1 ( + CTGATCTATCCAAGGGCTGGTG, _TTTCTCT CCTCCCTTCTTGTGTG), MDM2 ( + GGTTGACTCAGCTTTTCCTCTTG, _GGAA AATGCATGGTTTAAATAGCC).

Bioinformatics analyses. Gene expression data sets GSE3494, GSE11121, GSE2034 were downloaded from the GEO omnibus repository. Gene expression rank reflects relative mRNA expression level and is more consistent as it requires no normalization and thus introduces no normalization bias. ${ }^{59,60}$ Gene expression values were transformed into rank expression values on a scale from 100 to 0 . Rank value 55 means $55 \%$ of probes in the sample have lower measured expression values. We use Pearson coefficient as a measure of correlation between expression profiles.

Our primary aim is to divide samples in the data set into two cohorts so as to maximize positive correlation between expression profiles of $p 63$ and caspase-1 in cohort 1 and to minimize positive correlation in cohort 2 . We start with all samples in cohort 1 and no samples in cohort 2. We compute correlation between p63 and caspase-1 expression profiles in cohort 1, as well as compute the changes in correlation if one sample from the cohort would be removed. The sample with maximal effect on correlation (maximal increase in positive correlation) is moved from cohort 1 to cohort 2. The same procedure is repeated next until there would be no one sample, which could be removed from cohort 1 so to increase positive correlation between p63 and caspase-1. The separation of patients into 'cohort 1' and 'cohort 2' along with survival information was next used to find any statistical differences in survival outcome. The $\mathrm{R}$ statistical package was used to perform survival analyses and to draw KMplots.

\section{Conflict of Interest}

The authors declare no conflict of interest.

Acknowledgements. This work has been supported by the Medical Research Council, UK and funding from RFBS (10-04-01234), MCB RAS, Russian Federal grants 11.G34.31.0069 (to GM).

1. Yang A, Kaghad M, Wang Y, Gillett E, Fleming MD, Dotsch V et al. p63, a p53 homolog at 3q27-29, encodes multiple products with transactivating, death-inducing, and dominant-negative activities. Molecular cell 1998; 2: 305-316.
2. Levine AJ, Tomasini R, McKeon FD, Mak TW, Melino G. The p53 family: guardians of maternal reproduction. Nature reviews Molecular cell biology 2011; 12: 259-265.

3. Melino G. p63 is a suppressor of tumorigenesis and metastasis interacting with mutant p53. Cell Death Differ 2011; 18: 1487-1499.

4. Marcel V, Petit I, Murray-Zmijewski F, Goullet de Rugy T, Fernandes K, Meuray V et al. Diverse p63 and p73 isoforms regulate Delta133p53 expression through modulation of the internal TP53 promoter activity. Cell Death Differ 2012; 19: 816-826.

5. De Laurenzi V, Costanzo A, Barcaroli D, Terrinoni A, Falco M, Annicchiarico-Petruzzelli M et al. Two new p73 splice variants, gamma and delta, with different transcriptional activity. J Exp Med 1998; 188: 1763-1768.

6. Ghioni P, Bolognese F, Duijf PH, Van Bokhoven H, Mantovani R, Guerrini L. Complex transcriptional effects of p63 isoforms: identification of novel activation and repression domains. Mol Cell Biol 2002; 22: 8659-8668.

7. Yang A, Schweitzer R, Sun D, Kaghad M, Walker N, Bronson RT et al. p63 is essential for regenerative proliferation in limb, craniofacial and epithelial development. Nature 1999; 398: 714-718.

8. Romano RA, Smalley K, Magraw C, Serna VA, Kurita T, Raghavan S et al. DeltaNp63 knockout mice reveal its indispensable role as a master regulator of epithelial development and differentiation. Development 2012; 139: 772-782.

9. Shalom-Feuerstein R, Lena AM, Zhou H, De La Forest Divonne S, Van Bokhoven H, Candi E et al. DeltaNp63 is an ectodermal gatekeeper of epidermal morphogenesis. Cell Death Differ 2011; 18: 887-896.

10. Rufini S, Lena AM, Cadot B, Mele S, Amelio I, Terrinoni A et al. The sterile alpha-motif (SAM) domain of p63 binds in vitro monoasialoganglioside (GM1) micelles. Biochem Pharmacol 2011; 82: 1262-1268.

11. Graupner V, Alexander E, Overkamp T, Rothfuss O, De Laurenzi V, Gillissen BF et al. Differential regulation of the proapoptotic multidomain protein Bak by p53 and p73 at the promoter level. Cell Death Differ 2011; 18: 1130-1139.

12. Rufini A, Tucci $P$, Celardo I, Melino G. Senescence and aging: the critical roles of $p 53$. Oncogene 2013; e-pub ahead of print 18 February 2013; doi:10.1038/onc.2012.640.

13. Nayak G, Cooper GM. p53 is a major component of the transcriptional and apoptotic program regulated by PI 3-kinase/Akt/GSK3 signaling. Cell Death Dis 2012; 3: e400.

14. Huang Y, Chuang A, Hao H, Talbot C, Sen T, Trink B et al. Phospho-DeltaNp63alpha is a key regulator of the cisplatin-induced microRNAome in cancer cells. Cell Death Differ 2011; 18: $1220-1230$

15. Jeffers JR, Parganas E, Lee Y, Yang C, Wang J, Brennan $\mathrm{J}$ et al. Puma is an essential mediator of p53-dependent and -independent apoptotic pathways. Cancer cell 2003; 4: 321-328.

16. Nikulenkov $F$, Spinnler $C$, Li $H$, Tonelli $C$, Shi $Y$, Turunen $M$ et al. Insights into p53 transcriptional function via genome-wide chromatin occupancy and gene expression analysis. Cell Death Differ 2012; 19: 1992-2002.

17. Garrison SP, Phillips DC, Jeffers JR, Chipuk JE, Parsons MJ, Rehg JE et al. Genetically defining the mechanism of Puma- and Bim-induced apoptosis. Cell Death Differ 2012; 19: 642-649.

18. Yin C, Knudson CM, Korsmeyer SJ, Van Dyke T. Bax suppresses tumorigenesis and stimulates apoptosis in vivo. Nature 1997; 385: 637-640.

19. Wang X, Olberding KE, White C, Li C. BCl-2 proteins regulate ER membrane permeability to luminal proteins during ER stress-induced apoptosis. Cell Death Differ 2011; 18: 38-47.

20. Esposito F, Tornincasa M, Federico A, Chiappetta G, Pierantoni GM, Fusco A. High-mobility group A1 protein inhibits p53-mediated intrinsic apoptosis by interacting with Bcl-2 at mitochondria. Cell Death Dis 2012; 3: e383.

21. Galluzzi L, Vitale I, Abrams JM, Alnemri ES, Baehrecke EH, Blagosklonny MV et al. Molecular definitions of cell death subroutines: recommendations of the Nomenclature Committee on Cell Death 2012. Cell Death Differ 2012; 19: 107-120.

22. Gressner O, Schilling T, Lorenz K, Schulze Schleithoff E, Koch A, Schulze-Bergkamen $\mathrm{H}$ et al. TAp63alpha induces apoptosis by activating signaling via death receptors and mitochondria. The EMBO J 2005; 24: 2458-2471.

23. Suh EK, Yang A, Kettenbach A, Bamberger C, Michaelis AH, Zhu Z et al. p63 protects the female germ line during meiotic arrest. Nature 2006; 444: 624-628.

24. Gonfloni S, Di Tella L, Caldarola S, Cannata SM, Klinger FG, Di Bartolomeo C et al. Inhibition of the c-Abl-TAp63 pathway protects mouse oocytes from chemotherapy-induced death. Nature Med 2009; 15: 1179-1185.

25. Amelio I, Grespi F, Annicchiarico-Petruzzelli M, Melino G. p63 the guardian of human reproduction. Cell Cycle 2012; 11: 4545-4551.

26. Dhillon PK, Penney KL, Schumacher F, Rider JR, Sesso HD, Pollak M et al. Common polymorphisms in the adiponectin and its receptor genes, adiponectin levels and the risk of prostate cancer. Cancer Epidemiol Biomarkers Prev 2011; 20: 2618-2627.

27. Urist MJ, Di Como CJ, Lu ML, Charytonowicz E, Verbel D, Crum CP et al. Loss of p63 expression is associated with tumor progression in bladder cancer. Am J Pathol 2002; 161: 1199-1206.

28. Righi L, Graziano P, Fornari A, Rossi G, Barbareschi M, Cavazza A et al. Immunohistochemical subtyping of nonsmall cell lung cancer not otherwise specified in fine-needle aspiration cytology: a retrospective study of 103 cases with surgical correlation. Cancer 2011; 117: 3416-3423.

29. Hanker L, Karn T, Ruckhaeberle E, Gaetje R, Solbach C, Schmidt M et al. Clinical relevance of the putative stem cell marker p63 in breast cancer. Breast Cancer Res Treat 2010; 122: 765-775. 
30. Dusek RL, Bascom JL, Vogel H, Baron S, Borowsky AD, Bissell MJ et al. Deficiency of the p53/p63 target Perp alters mammary gland homeostasis and promotes cancer. Breast Cancer Res 2012; 14: R65.

31. Insabato L, Amelio I, Quarto M, Zannetti A, Tolino F, de Mauro G et al. Elevated expression of the tyrosine phosphatase SHP-1 defines a subset of high-grade breast tumors. Oncology 2009; 77: 378-384.

32. Wang TY, Chen BF, Yang YC, Chen H, Wang Y, Cviko A et al. Histologic and immunophenotypic classification of cervical carcinomas by expression of the p53 homologue p63: a study of 250 cases. Hum Pathol 2001; 32: 479-486.

33. Quade BJ, Yang A, Wang Y, Sun D, Park J, Sheets EE et al. Expression of the p53 homologue p63 in early cervical neoplasia. Gynecol Oncol 2001; 80: 24-29.

34. Massion PP, Taflan PM, Jamshedur Rahman SM, Yildiz P, Shyr Y, Edgerton ME et al. Significance of p63 amplification and overexpression in lung cancer development and prognosis. Cancer Res 2003; 63: 7113-7121.

35. Kogan-Sakin I, Tabach Y, Buganim Y, Molchadsky A, Solomon H, Madar S et al. Mutant p53(R175H) upregulates Twist1 expression and promotes epithelial-mesenchyma transition in immortalized prostate cells. Cell Death Differ 2011; 18: 271-281.

36. Aoubala M, Murray-Zmijewski F, Khoury MP, Fernandes K, Perrier S, Bernard H et al. p53 directly transactivates Delta133p53alpha, regulating cell fate outcome in response to DNA damage. Cell Death Differ 2011; 18: 248-258.

37. Adorno M, Cordenonsi M, Montagner M, Dupont S, Wong C, Hann B et al. A Mutant-p53/ Smad complex opposes p63 to empower TGFbeta-induced metastasis. Cell 2009; 137 87-98.

38. Tucci P, Agostini M, Grespi F, Markert EK, Terrinoni A, Vousden KH et al. Loss of p63 and its microRNA-205 target results in enhanced cell migration and metastasis in prostate cancer. Proc Natl Acad Sci USA 2012; 109: 15312-15317.

39. Gatta R, Dolfini D, Mantovani R. NF-Y joins E2Fs, p53 and other stress transcription factors at the apoptosis table. Cell Death Dis 2011; 2: e162.

40. Seervi M, Joseph J, Sobhan PK, Bhavya BC, Santhoshkumar TR. Essential requirement of cytochrome $\mathrm{c}$ release for caspase activation by procaspase-activating compound defined by cellular models. Cell Death Dis 2011; 2: e207.

41. Bouchier-Hayes L, Green DR. Caspase-2: the orphan caspase. Cell Death Differ 2012; 19 51-57.

42. Miao EA, Rajan JV, Aderem A. Caspase-1-induced pyroptotic cell death. Immunol Rev 2011; 243: 206-214.

43. Zhang WH, Wang X, Narayanan M, Zhang Y, Huo C, Reed JC et al. Fundamental role of the Rip2/caspase-1 pathway in hypoxia and ischemia-induced neuronal cell death. Proc Natl Acad Sci USA 2003; 100: 16012-16017.

44. Hu B, Elinav E, Huber S, Booth CJ, Strowig T, Jin C et al. Inflammation-induced tumorigenesis in the colon is regulated by caspase-1 and NLRC4. Proc Natl Acad Sci USA 2010; 107: 21635-21640.

45. Denes A, Lopez-Castejon G, Brough D. Caspase-1: is IL-1 just the tip of the ICEberg? Cell Death Dis 2012; 3: e338.

46. Winter RN, Kramer A, Borkowski A, Kyprianou N. Loss of caspase-1 and caspase-3 protein expression in human prostate cancer. Cancer Res 2001; 61: 1227-1232.

47. Ummanni R, Lehnigk U, Zimmermann U, Woenckhaus C, Walther R, Giebel J Immunohistochemical expression of caspase- 1 and -9 , uncleaved caspase-3 and -6 , cleaved caspase- 3 and -6 as well as $\mathrm{Bcl}-2$ in benign epithelium and cancer of the prostate. Exp Ther Med 2010; 1: 47-52.

48. Koga F, Kawakami S, Fujii Y, Saito K, Ohtsuka Y, Iwai A et al. Impaired p63 expression associates with poor prognosis and uroplakin III expression in invasive urothelial carcinoma of the bladder. Clin Cancer Res 2003; 9: 5501-5507.

49. Barbieri CE, Tang LJ, Brown KA, Pietenpol JA. Loss of p63 leads to increased cell migration and up-regulation of genes involved in invasion and metastasis. Cancer Res 2006; 66: 7589-7597.

50. Arredouani MS, Lu B, Bhasin M, Eljanne M, Yue W, Mosquera JM et al. Identification of the transcription factor single-minded homologue 2 as a potential biomarker and immunotherapy target in prostate cancer. Clinical Cancer Res 2009; 15: 5794-5802.

51. Varambally S, Yu J, Laxman B, Rhodes DR, Mehra R, Tomlins SA et al. Integrative genomic and proteomic analysis of prostate cancer reveals signatures of metastatic progression. Cancer Cell 2005; 8: 393-406.

52. Stransky N, Vallot C, Reyal F, Bernard-Pierrot I, de Medina SG, Segraves R et al. Regional copy number-independent deregulation of transcription in cancer. Nature Genetics 2006; 38: 1386-1396.

53. Cheng W, Jacobs WB, Zhang JJ, Moro A, Park JH, Kushida M et al. DeltaNp63 plays an anti-apoptotic role in ventral bladder development. Development 2006; 133: 4783-4792.

54. Comperat E, Camparo P, Haus R, Chartier-Kastler E, Bart S, Delcourt A et al. Immunohistochemical expression of p63, p53 and MIB-1 in urinary bladder carcinoma. A tissue microarray study of 158 cases. Virchows Arch 2006; 448: 319-324.

55. Park BJ, Lee SJ, Kim Jl, Lee CH, Chang SG, Park JH et al. Frequent alteration of p63 expression in human primary bladder carcinomas. Cancer research 2000; 60: 3370-3374

56. Signoretti S, Waltregny D, Dilks J, Isaac B, Lin D, Garraway L et al. p63 is a prostate basal cell marker and is required for prostate development. Am J Pathol 2000; 157: 1769-1775.

57. Grisanzio C, Signoretti S. p63 in prostate biology and pathology. J Cell Biochem 2008; 103 : 1354-1368.

58. Quandt K, Frech K, Karas H, Wingender E, Werner T. Matlnd and MatInspector: new fast and versatile tools for detection of consensus matches in nucleotide sequence data. Nucleic Acids Res 1995; 23: 4878-4884.

59. Antonov AV, Knight RA, Melino G, Barlev NA, Tsvetkov PO. MIRUMIR: an online tool to test microRNAs as biomarkers to predict survival in cancer using multiple clinical data sets. Cell Death Differ 2013; 20: 367

60. Antonov AV. BioProfiling.de: analytical web portal for high-throughput cell biology. Nucleic Acids Res 2011; 39(Web Server issue): W323-W327.

(c) $(1)(\theta)$ Cell Death and Disease is an open-access journal published by Nature Publishing Group. This work is licensed under a Creative Commons Attribution-NonCommercialNoDerivs 3.0 Unported License. To view a copy of this license, visit http://creativecommons.org/licenses/by-nc-nd/3.0/ 